\title{
Towards higher temperatures in nuclear waste repositories
}

\author{
Antonio Gens ${ }^{1 *}$, Ramon B. de Vasconcelos ${ }^{2}$, and Sebastià Olivella ${ }^{1}$ \\ ${ }^{1}$ Department of Civil and Environmental Engineering, Universitat Politècnica de Catalunya (UPC), 08034 Barcelona, Spain \\ ${ }^{2}$ International Centre for Numerical Methods in Engineering (CIMNE), 08034 Barcelona Spain
}

\begin{abstract}
Recently, there is a tendency to explore the possibility of increasing the maximum design temperature in deep geological repositories for high-level nuclear waste and spent fuel. In the paper, a number of issues related to the use of higher temperatures are reviewed. Both bentonite barriers and argillaceous host rocks are addressed. An application involving the modelling of a large-scale field test conducted at a maximum temperature of $140^{\circ} \mathrm{C}$ is presented. It is shown that currently available theoretical formulations and computer codes are capable to deal with temperatures above $100^{\circ} \mathrm{C}$ and to reproduce satisfactorily the thermally-induced overpressures in the rock.
\end{abstract}

\section{Introduction}

One of the key issues in nuclear energy utilization is the safe storage and disposal of high-level nuclear waste (HLW) and spent fuel (SF). There is general agreement that deep geological disposal is very probably the most feasible and effective solution and a large amount of work is being undertaken towards this goal [1-4]. A typical scheme for a deep geological repository is depicted in Figure 1.

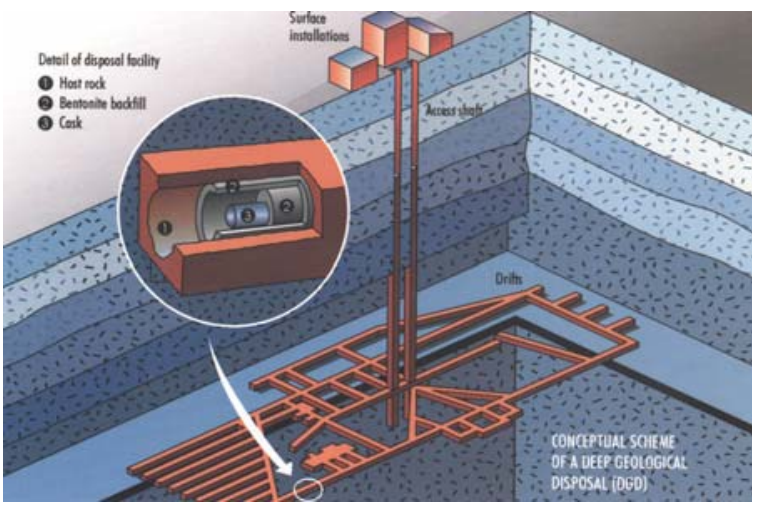

Fig. 1. Conceptual scheme of a deep geological repository

Most designs rely on the multi-barrier approach to provide an appropriate long-term isolation of the radioactive waste. It consists of a number of barriers (e.g. canister, bentonite buffer, host rock) jointly contributing to separate the waste from the biosphere and to ensure that any residual doses will be well below the allowed values (Figure 2).

An important feature of high-level nuclear waste and spent nuclear fuel is that the waste packages are heatemitting. Although the waste will be kept at the surface for a significant period, an increase of temperature in the buffer and host rock is unavoidable and thermal effects must be taken into account; they affect mainly the bentonite barrier and the host rock in the immediate vicinity. In this context, the maximum temperature that will be reached in the repository is an important design parameter.

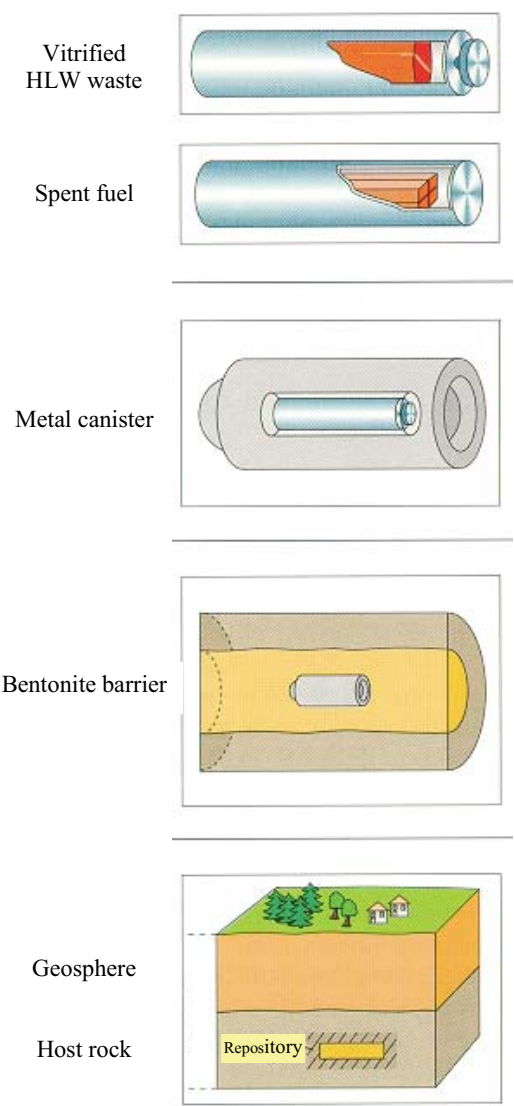

Fig. 2. Multi-barrier concept for the confinement of nuclear waste

\footnotetext{
* Corresponding author: antonio.gens@upc.edu
} 
Because of the complexity of the interacting thermohydro-mechanical (THM) phenomena taking place in the repository and the requirement for long-term predictions, coupled THM numerical analyses are necessary for achieving an adequate understanding of the problem.

Generally, most repository concepts establish a design criterion of $100^{\circ} \mathrm{C}$ for the maximum temperature in the bentonite buffer [e.g. 5, 6]. More recently, however, the possibility of allowing the maximum design temperature to reach values well above $100^{\circ} \mathrm{C}$ is being explored. Permitting higher temperatures implies that the waste packages can be placed closer together, thus reducing the cost of the repository. However, the implications of accepting higher temperatures have not been fully examined yet.

The paper discusses some selected issues related to the behavior of bentonite barriers and argillaceous host rocks at higher temperatures. Special, but not exclusive, attention is paid to matters related to theoretical formulations. Afterwards, a modelling application to a high-temperature large-scale test, performed in an underground research laboratory, is presented.

\section{Bentonite barriers at higher temperatures}

As the possibility of applying temperatures higher than $100^{\circ} \mathrm{C}$ to bentonite barriers is being contemplated, it is interesting to examine what is the impact on the formulations commonly used for coupled THM analysis.

It is well known that pure free water, at $0.1 \mathrm{MPa}$ pressure, boils at $100^{\circ} \mathrm{C}$. This is reflected in the water pressure-enthalpy diagram shown in Figure 3 . It is recalled that enthalpy is the sum of the internal energy plus the product of pressure and volume. In an enclosed system at constant pressure, enthalpy changes equal the heat absorbed or released. Three zones can be distinguished: zone 1 is a single-phase region (liquid water), zone 2 is a two-phase region (liquid water and vapour) and zone 3 is again a single-phase region (vapour). It can be noted that the transformation of liquid water into vapour requires the addition of heat while temperature stays constant.

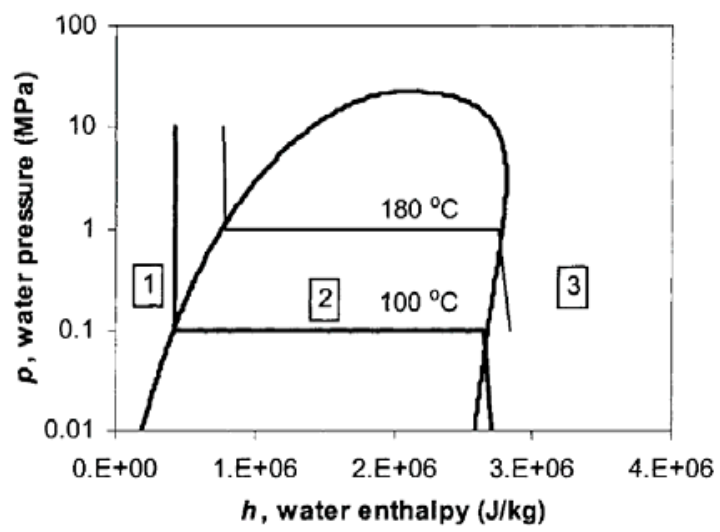

Fig. 3. Pressure enthalpy diagram for pure free water
However, the water in an initially unsaturated bentonite barrier in a repository is not free water but it is subjected to a potential that can be related to suction (i.e. suction is the potential per unit volume with the sign changed). Matric potential can be viewed as the degree of attachment (in energy terms) of the water substance to the solid phase. In addition, in an unsaturated state, air is also present in the pores. The situation is now more complex and the behaviour represented in Figure 3 must be modified.

There are a number of features that must be taken into account:

- Liquid water and water vapour have different pressures

- Degree of saturation is related to suction by the retention curve

- Vapour density is modified by suction according to Kelvin's (psychrometric) law

- Surface tension is dependent on temperature,

It should be noted that those items above correspond to a conventional thermo-hydraulic formulation, no especial provision has been made for temperatures higher than $100^{\circ} \mathrm{C}$. Thus, according to this approach, thermal and suction effects on water will be the result of the combination of retention curve, psychrometric law and surface tension variation. For simplicity, no distinction is made between pore water and interlayer water at this stage. Further details are given in [7].

To illustrate the performance of the formulation, a number of retention curves corresponding to different soil types are considered. The van Genuchten [8] expression is used:

$$
S_{e}=\left[1+\left(\frac{P_{g}-P_{l}}{P}\right)^{1 /(1-\lambda)}\right]^{-\lambda}
$$

where $S_{e}$ is the effective degree of saturation, $P_{g}$ the gas pressure, $P_{l}$ the liquid pressure and $P$ and $\lambda$ are parameters. Parameter $P$ is related to the air entry value of the soil that, in turn, depends on the pore size of the material. Air entry value also varies with surface tension of water.

If an analogy is made with a capillary model, the effects of temperature on surface tension can be accounted for by considering a variation of the parameter $P[9]$ as:

$$
P=P_{0} \frac{\sigma(T)}{\sigma\left(T_{0}\right)}
$$

where $\sigma$ is surface tension and $T$ is temperature. The subscript 0 indicates a reference situation. A range of values of $P_{0}\left(1,10^{-3}, 10^{-6}\right.$ and $\left.10^{-7} \mathrm{MPa}\right)$ will be considered. The higher the value of $P$, the more fine grained the material is and the higher the air entry value becomes.

Now, heat (enthalpy) is applied to an initially saturated sample. A constant liquid water pressure equal to $0.1 \mathrm{MPa}$ is prescribed. Figure 4 shows the variation of temperature as enthalpy increases. It can now be observed that, considering the water in a porous material, the temperature does not show a plateau on reaching $100^{\circ} \mathrm{C}$ but it keeps increasing up to quite high values. The effect on degree of saturation is shown in Figure 5. 
It can be noted that the degree of saturation reduces gradually, not all the water becomes vapour on reaching $100^{\circ} \mathrm{C}$. In fact, the higher the suction effects are, the more gradual the degree of saturation reduction is. Thus, for a given value of enthalpy a certain amount of water has not evaporated yet and part of the heat is used to increase the temperature instead of changing the phase of the remaining water.

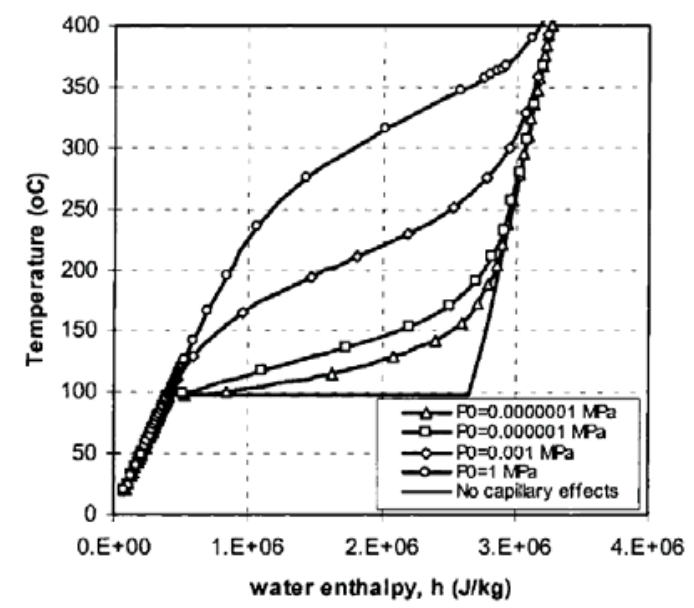

Fig. 4. Variation of temperature with water enthalpy for soils with different retention curves

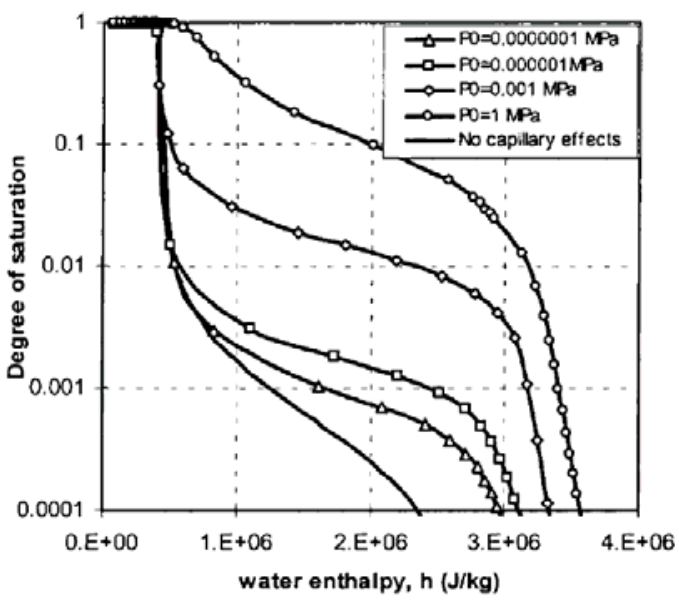

Fig. 5. Variation of degree of saturation with water enthalpy for soils with different retention curves

Finally, the variation of vapour pressure as a function of water enthalpy is plotted in Figure 6. In fine-grained soils, the difference between vapour pressure and liquid pressure $(0.1 \mathrm{MPa})$ can attain very large values. It should be noted that all the curves in Figures 4, 5 and 6 correspond to equilibrium states.

For simplicity, in many THM analysis, the gas flow equation is not included in the set of equations to be solved and it is assumed that the gas pressure is constant and equal to atmospheric pressure. Since vapour pressure can reach high values, care should be taken that, implicitly, the air pressure does not become negative; an unrealistic situation.

Therefore, modelling of bentonite barriers does not appear to require additional formulation developments.
However, it is still necessary to examine whether the higher temperatures affect the behaviour of the material. One issue concerns possible mineral modifications, but this topic is not discussed in this paper. Regarding THM properties, the experimental evidence is mixed $[10,11]$. A review [12] concluded that changes of THM properties when the temperature was below $120^{\circ} \mathrm{C}$ appear to be slight but the information for high temperatures was scarce and should be completed. In particular, the effect of higher temperatures on thermal conductivity and water retention curves should be carefully studied as well as the potential effects of long term exposure of bentonite to vapour. It should also be remarked that most studies have been conducted on compacted bentonite, the new generation of pelletsbased materials will require a similar amount of effort. Therefore, a significant amount of experimental research on bentonite at high temperatures is still required.

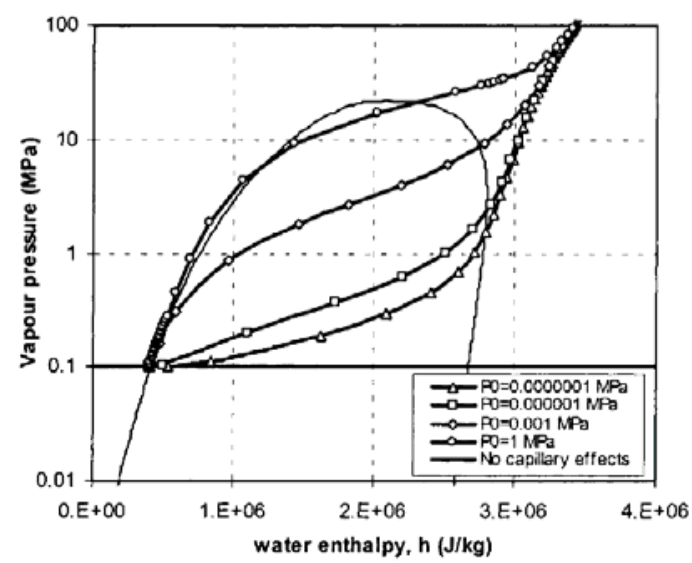

Fig. 6. Variation of vapour pressure with water enthalpy for soils with different retention curves

\section{Clayey host rocks at higher temperatures}

A number of countries (e.g. Belgium, France, Switzerland) plan to construct their repositories in argillaceous host rocks that are potentially susceptible to thermal effects. Increasing the maximum temperature in the repository automatically leads to higher temperatures in the geological barrier, although temperature will always be below $100^{\circ} \mathrm{C}$ in the host rock.

An important issue associated with temperature increase in a saturated host rock is the generation of overpressures that may lead to hydraulic fracture if the pore pressure becomes larger than the in-situ minor principal stress. This phenomenon has been observed both in the field and in the laboratory $[13,14]$

The main driving mechanism for this phenomenon is the higher water thermal dilatancy compared to the thermal expansion of the rock itself. As argillaceous rocks have very low permeability, the resulting pore pressures dissipate slowly. In fact, the generation of overpressures is more complex than this simple picture. It results from the combined effects of the thermal dilation of water, solid mineral and rock skeleton, the 
rate of pore water dissipation, the deformation of the soil skeleton due to changes in effective stresses and temperature, and the deformation of the solid mineral and water phase due to changes in applied pressures.

The complex coupling of all those phenomena is better understood by examining the solid mass and water mass balance equations:

$$
\begin{gathered}
\frac{\partial}{\partial t}\left(\rho_{s}(1-\phi)\right)+\nabla \cdot\left(\mathbf{j}_{s}\right)=0 \\
\frac{\partial}{\partial t}\left(\rho_{w} \varphi\right)+\nabla \cdot\left(\mathbf{j}_{w}\right)=f^{w}
\end{gathered}
$$

where $\phi$ is porosity, $\rho_{s}$ solid density, $\rho_{w}$ water density, $\mathbf{j}_{\mathrm{s}}$ total solid mass flux, $\mathbf{j}_{\mathrm{w}}$ total water mass flux and $f^{w}$ a water source/sink term.

Using the definition of material derivative

$$
\frac{D_{s}(\bullet)}{D t}=\frac{\partial(\bullet)}{\partial t}+\frac{d \mathbf{u}}{d t} \cdot \nabla(\bullet)
$$

where $\mathbf{u}$ is the displacement vector, equation (3) becomes

$$
\frac{D_{s} \phi}{D t}=\frac{1}{\rho_{s}}\left[(1-\phi) \frac{D_{s} \rho_{s}}{D t}\right]+(1-\phi) \nabla \cdot \frac{d \mathbf{u}}{d t}
$$

The new form of the solid mass balance equation (6) can now be incorporated in the water mass balance equation (4), resulting in

$$
\begin{aligned}
& \varphi \frac{D_{s} \rho_{w}}{D t}+\frac{\rho_{w}}{\rho_{s}} \cdot(1-\varphi) \cdot \frac{D_{s} \rho_{s}}{D t}+\rho_{w} \cdot \nabla \cdot \frac{d \mathbf{u}}{d t}+ \\
& +\nabla \cdot\left(\rho_{w} \cdot q_{l}\right)=0
\end{aligned}
$$

This equation can be further developed taking into account the effect of temperature and pressures on liquid and solid densities according to:

$$
\begin{gathered}
\rho_{w}=\rho_{w 0} \cdot \exp \left[\beta_{w}\left(p_{l}-p_{l o}\right)+b_{w} \cdot T\right] \\
\rho_{s}=\rho_{s 0} \cdot \exp \left[\beta_{s}\left(p_{s}-p_{s o}\right)+3 \cdot b_{s} \cdot\left(T-T_{r e f}\right)\right]
\end{gathered}
$$

where $\beta_{s}$ and $\beta_{w}$ are the solid and water compressibilities and $b_{s}$ and $b_{w}$ are the thermal expansion coefficients for solid and water components.

Expanding equation (7), the following equation finally results:

$$
\begin{aligned}
& {\left[\phi \cdot b_{w}+(1-\phi) \cdot 3 \cdot b_{s}\right] \cdot \frac{D_{s} T}{D t}+\phi \cdot \beta_{w} \cdot \frac{D_{s} P_{w}}{D t}+} \\
& +(1-\phi) \cdot \beta_{s} \cdot \frac{D_{s} p_{s}}{D t}+\nabla \cdot \frac{d \mathbf{u}}{d t}+\frac{\nabla \cdot\left(\rho_{w} \cdot q_{l}\right)}{\rho_{w}}=0
\end{aligned}
$$

The various couplings can now be readily examined. The first term expresses the thermal expansion of solid and liquid phases. The second and third terms are the volume changes of water and solid phase associated with pressure changes, the fourth term is the volume change of the material skeleton (includes contributions from stresses, pore pressures and temperature) and the fifth term is the volume change associated with the flow of water in or out of the element considered. The pore pressure generated will be the result of the interaction of all those terms in each particular case.

A different issue concerning the effect of temperature on the behaviour of argillaceous rocks has arisen from recent experimental work. It would be normally expected that, in these very stiff materials, a temperature increase would give rise to a largely reversible expansion. However, recent experimental results have shown that irreversible contractile strains associated with a temperature rise are possible. An example is shown in Figure 7 where the volumetric strain observed in an Opalinus clay sample subjected to two cycles of temperature increase/reduction are plotted [15]. It can be noted that, in the first cycle, contraction follows a dilatant behaviour when the temperature reaches about $65^{\circ} \mathrm{C}$. Contraction is not observed during the temperature rise of the second cycles suggesting a thermoplastic behaviour.

Intriguingly, the temperature threshold for contractive strains appeares to be close to the estimated maximum temperature experienced by the rock throughout its geological history. The same type of observations, including the change of behaviour when reaching the maximum past temperature of the rock, has been reported for the COx claystone [16].

Although those unexpected observations have to be further confirmed, the reported behaviour of those two argillaceous rocks suggests that another maximum rock temperature criterion may be introduced if thermoplastic strains are to be avoided. It would correspond to the maximum temperature that the rock has been subjected to during its geological history.

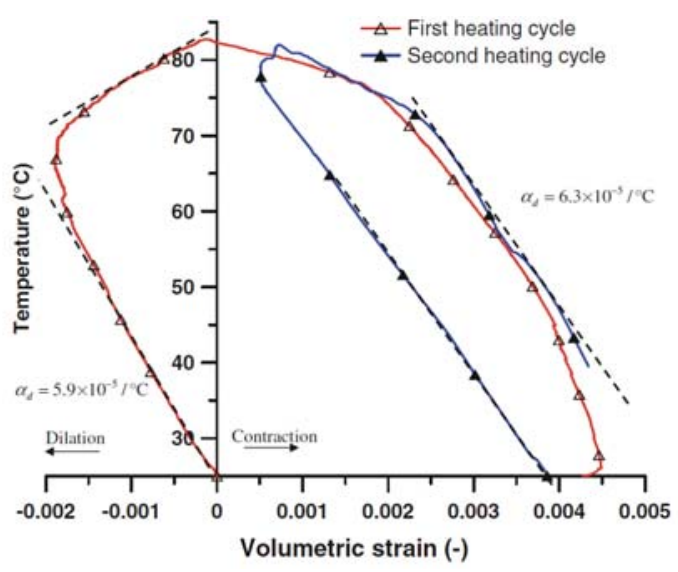

Fig. 6. Volumetric strains observed during a drained heating/ cooling test on Opalinus clay (modified from [15]). $\alpha_{d}$ is the volumetric expansion coefficient of the porous skeleton

\section{Application}

In this section, a numerical simulation of a field test (HE-E) is presented. It involves two of the features discussed above: a bentonite-based barrier at a temperature higher than $100^{\circ} \mathrm{C}$ and the generation of thermally-induced overpressures in the host rock.

The HE-E experiment is a large-scale heating test where the engineered barrier is subjected to a temperature of $140^{\circ} \mathrm{C}$. The test is being performed in the Opalinus Clay formation at the Mont Terri URL (Switzerland), in a $50 \mathrm{~m}$ long microtunnel (MT) $1.3 \mathrm{~m}$ in diameter. The test section has a length of $10 \mathrm{~m}$ and it is divided in two independently heated sections (identified as NAGRA Section and GRS Section) $4 \mathrm{~m}$-long each, in 
which the heaters are placed (Figure 7). A pedestal of compacted MX-80 bentonite blocks support the two heaters. The space between the host rock wall, the compacted bentonite blocks and the heaters is backfilled with bentonite-based materials. The NAGRA section uses MX-80 bentonite pellets and the GRS section is filled with a sand-bentonite mixture with $65 \%$ of sand and $35 \%$ of bentonite. The test sections have been isolated from the external environment by two concrete plugs. A third concrete barrier separates the two sections. In addition, a thermal insulation and a vapour barrier have also been constructed. Figure 8 shows the insertion of the heaters into the test section of the tunnel and Figure 9 illustrates the emplacement of the granular bentonite barrier. Further details are given in [17]. The test was instrumented with sensors placed in the bentonite barrier and in the Opalinus clay (Figure 10). Pore pressures were also measured in the far field at distances between 3 and $6 \mathrm{~m}$ from the tunnel wall.

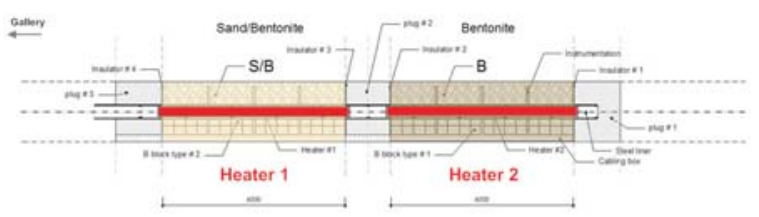

Fig. 7. Schematic layout of the HE-E experiment showing the location of the two heaters

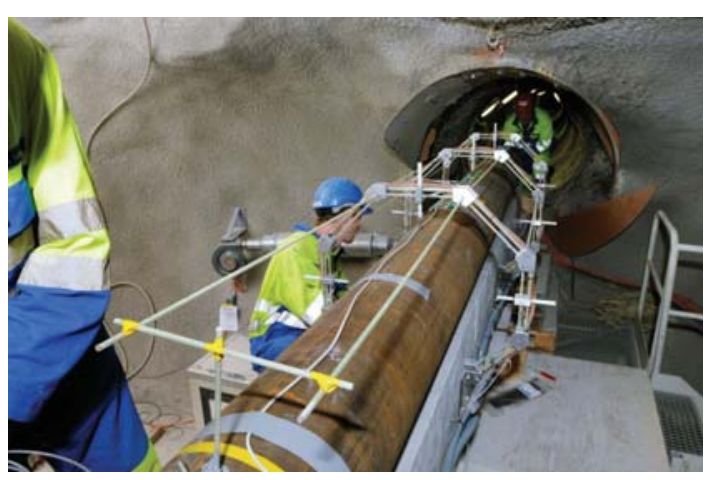

Fig. 8. HE-E experiment. Insertion of the heaters in the test area

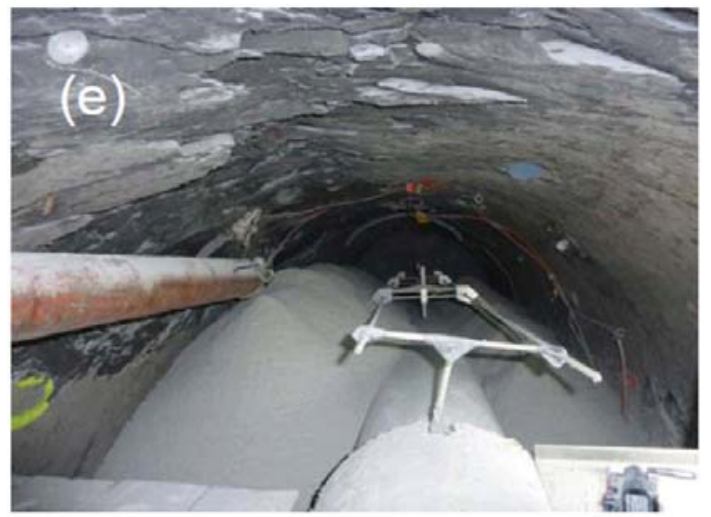

Fig. 9. HE-E experiment. Emplacement of the granular bentonite by auger
The performance of the test involved a transient temperature rise with the heaters maintained at constant power. After the $140^{\circ} \mathrm{C}$ designated temperature was reached, it has been kept constant throughout. The test is still operating nearly 9 years after the start of heating. No artificial hydration is provided, the hydration of the barrier is by water supplied by the host rock. Because the Opalinus clay has a very low permeability, the amount of hydration, even after 9 years is quite limited.

The test was analysed using a conventional THM formulation and the computer code CODE BRIGHT $[18,19]$. As indicated above, no modifications were introduced although the maximum temperature in the barrier was kept at $140^{\circ} \mathrm{C}$. The formulation involves the simultaneous consideration of the equations for mass balance of solid, mass balance of water, internal energy balance and equilibrium.

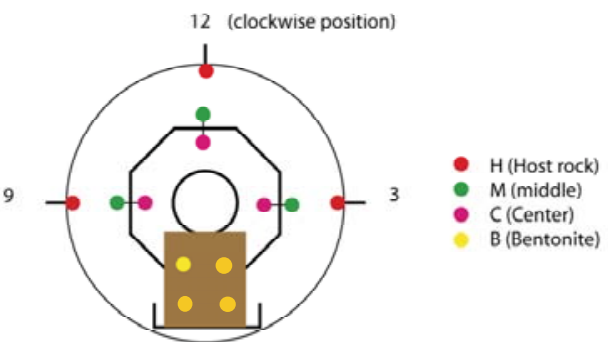

a)

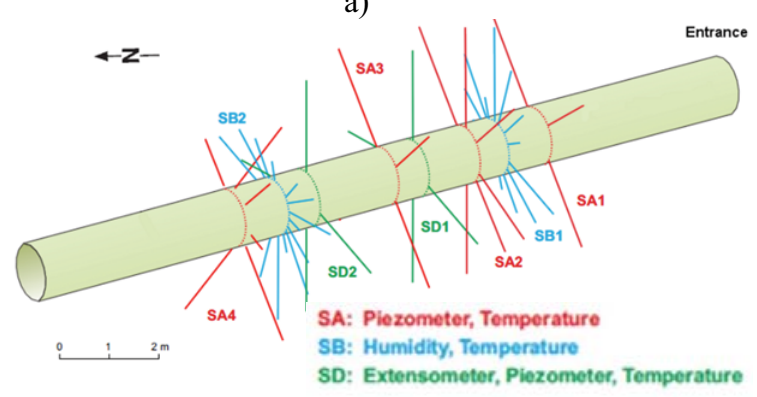

b)

Fig. 10. HE-E experiment. Instrumentation: a) bentonite barrier, b) Opalinus clay

The thermo-hydraulic properties of the barrier materials were characterized by a programme of laboratory tests on the barrier materials. As an example, Figure 11 shows the assumed variation of thermal conductivity with degree of saturation for compacted blocks and granular bentonite. The use of a realistic dependence of thermal conductivity with degree of saturation is key for a correct prediction of temperatures in the barrier and beyond.

An axisymmetric analysis domain was used in the calculations reported here. The simulation included the excavation of the tunnel, the ventilation period before test installation and the heating stage taken to very long times. The results of the analysis are compared with observations, the latest sensor data corresponds to day 2833 from the start of heating. Only some selected results of the analyses for the NAGRA section (MX-80 pellets) are presented. Full details of the model assumptions, geometry, boundary and initial conditions, 
material parameters and simulation results are provided in [20].

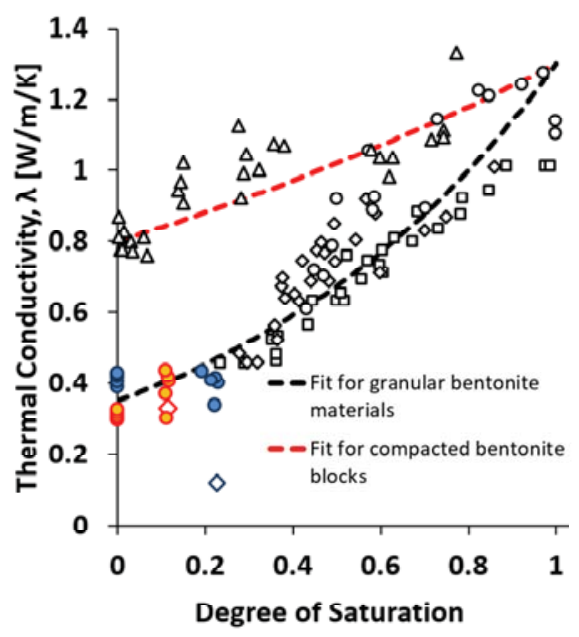

Fig. 11. Variation of thermal conductivity with degree of saturation for compacted blocks and granular bentonite

Figure 12 shows the history of the temperature in the contact between the heater and the bentonite barrier where the $140^{\circ} \mathrm{C}$ temperature has been maintained. The corresponding evolution of heater power is plotted in Figure 13; a good agreement is obtained indicating a correct estimation of the thermal conductivity of the barrier and rock. The difference of power between the two heaters is due to a small difference between the thermal conductivities of the two barrier materials. The increase of heater power with time reflects the increase in thermal conductivity due to hydration. It can be observed that the increase is very slight because the rate of hydration from the Opalinus clay is very limited.

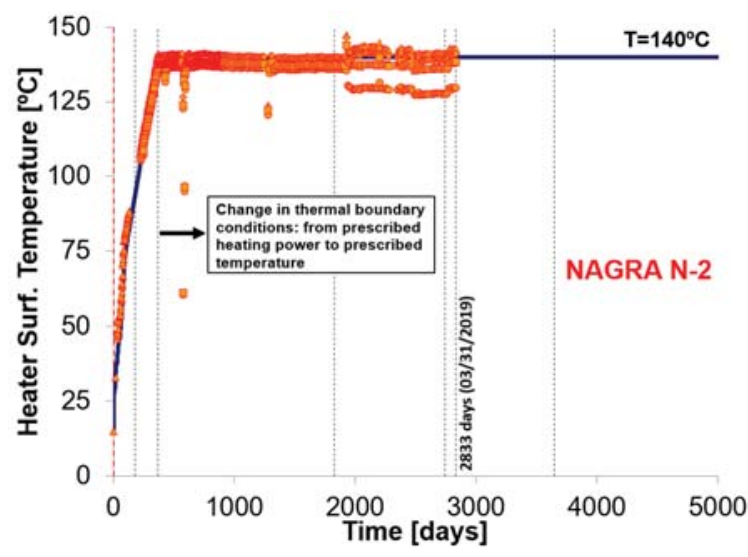

Fig. 12. History of the heater temperature in the NAGRA section. Symbols correspond to observations

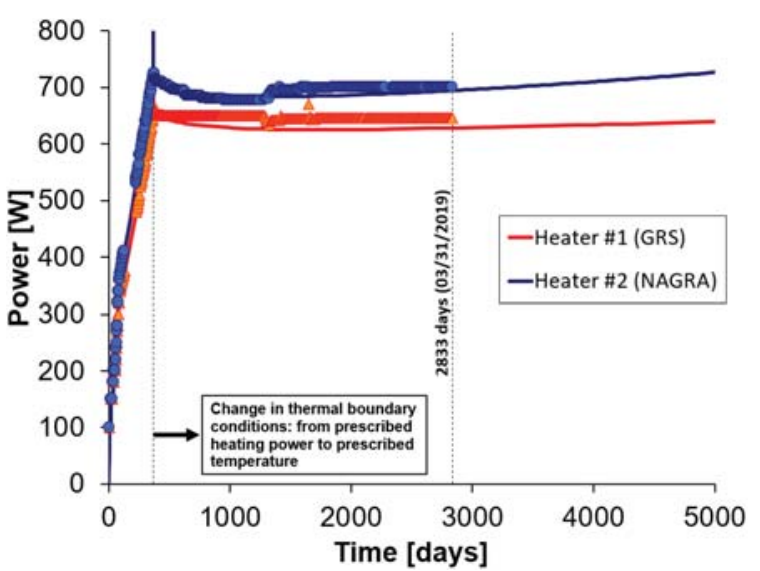

Fig. 13. Computed and observed evolutions of the power for the two heaters in the experiment. Symbols correspond to observations

Figure 14 shows the computed and observed distributions of temperatures at various times in the barrier and in the Opalinus clay; a good agreement is again obtained. The very abrupt drop in temperature in the barrier can be noted. It is due to the quite low thermal conductivity of the granular bentonite when it is very far form saturation. When the barrier will become more hydrated, the high temperatures will gradually penetrate the barrier. It can be observed that the temperature distribution is quite steady in the barrier while there is a modest temperature increase with time in the Opalinus clay.

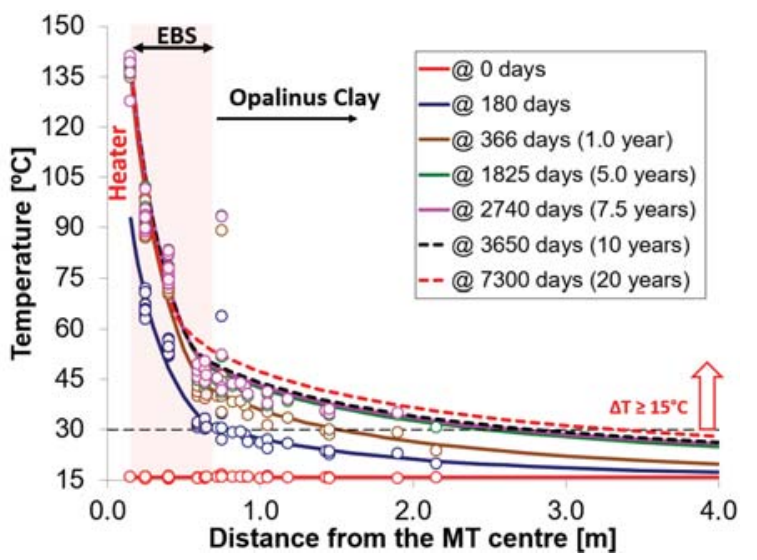

Fig. 14. Computed and observed distributions of temperature in the bentonite barrier and in the Opalinus clay at various times. NAGRA section. Symbols correspond to observations

The computed and observed evolutions of relative humidity at three points of the barrier are presented in Figure 15. It can be noted that strong drying occurs due to the high temperatures reached; only the sensor close to the rock shows clear signs of hydration. The value of relative humidity in the centre of the barrier is overestimated by the analysis; this is probably due to an insufficient characterization of the retention curve of the granular bentonite at high temperatures. 


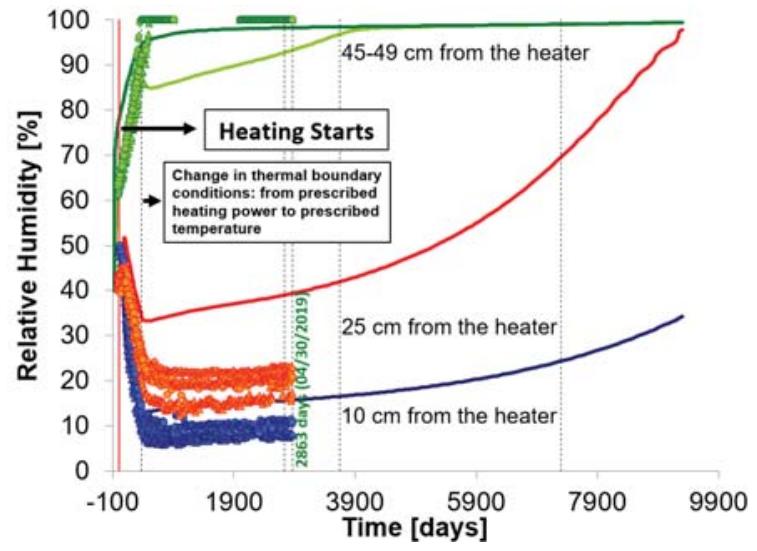

Fig. 15. Computed and observed evolutions of relative humidity in the bentonite barrier. NAGRA section. Symbols correspond to observations

Finally, Figure 16 shows the evolutions of the computed and observed thermally-induced overpressures with time in three sensors located in the far field of the experiment (3 to $6 \mathrm{~m}$ away from the tunnel wall). It can be clearly observed how the pore pressure in the rock reacts to the increase in temperature. However, after some time (450 to 650 days depending on location), the overpressures reach a peak and start to reduce because pore pressure dissipation overcomes the effects of temperature increase. The further way the sensor is from the tunnel, the later the time at which the peak overpressure is reached. It can be observed that the computed evolutions agree well with the magnitude and pattern of observations. A sudden increase of the observed pressures at around day 2500, not reproduced by the analysis, is clearly visible. This increase is a result of the start of a new test in the underground laboratory that affects the far field pressures and was not part of the HE-E experiment.

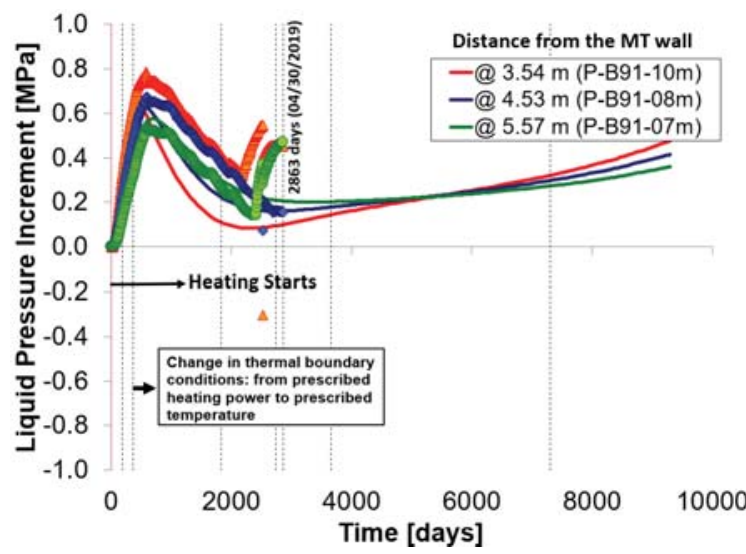

Fig. 16. Computed and observed evolutions of overpressures in the far field. Symbols correspond to observations

\section{Concluding remarks}

A number of issues associated with the adoption of higher maximum temperatures in the design of deep geological repositories for high-level nuclear waste and spent fuel have been reviewed. It has been demonstrated that no changes in the theoretical formulations are required when temperatures rise beyond $100^{\circ} \mathrm{C}$ although attention must be paid to the resulting value of air pressure if a constant gas pressure is assumed. On the other hand, more research is required to check the possible effects of high temperature on the THM properties of the various forms of bentonite materials, particularly for temperatures above $120^{\circ} \mathrm{C}$.

In argillaceous host rocks, higher temperatures will lead to larger overpressures that may become an issue if they reach values close to the minor principal stress. Also, the potential change of the thermomechanical rock behaviour when reaching temperatures higher than those experienced during its geological history deserves further attention.

The successful modelling of a large-scale field heating test that attains a temperature of $140^{\circ} \mathrm{C}$ indicates that currently available coupled numerical formulations and computer codes are capable of dealing with engineering problems involving higher temperatures.

\section{Acknowledgements}

The technical and financial support of ENRESA, NAGRA and the Mont Terri project are gratefully acknowledged.

\section{References}

1. W.E. Falck, K.-F. Nilsson. Geological Disposal of Radioactive Waste: Moving Towards Implementation. JRC European Commission (Report EUR 23925 EN, 2009)

2. IAEA. Geological Facilities for Radioactive Waste: specific safety guide. No. SSG-14 (Vienna: International Atomic Energy Agency, 2011)

3. B. Faybishenko, J. Birkholzer, D. Sassani, P. Swift. International Approaches for Deep Geological Disposal of Nuclear Waste: Geological Challenges in Radioactive Waste Isolation. Fifth Worldwide Review. LBNL-1006984, (Lawrence Berkeley National Laboratory, Sandia National Laboratories, 2016)

4. A. Gens, A. The role of geotechnical engineering in nuclear energy utilization. Proc. 13th. Eur. Conf. Soil Mech. Geotech. Engng, Prague 3, 25-67 (2003).

5. L.H. Johnson, D.M. Leneveu, D.W. Shoesmith, D.W. Oscarson, M.N. Gray, R.J. Lemire, N.C. Garisto, N.C., The vault model for postclosure assessment. AECL-10714 (Canada: AECL Research Report, 1994)

6. SKB. Waste, repository design and sites. SKB Technical Report TR-99-08 (Stockholm: SKB, 1999) 
7. S. Olivella, A. Gens. Vapour transport in low permeability unsaturated soils with capillary effects. Transp. in Por. Media, 40, 219-241 (2000)

8. R. van Genuchten, A closed-form equation for predicting the hydraulic conductivity of unsaturated soils. Soil Sci. Soc. Am. J., 44, 892-898 (1980)

9. S.A. Grant, A. Salehzadeh, Calculation of temperature effects on wetting coefficients of porous solids and their capillary pressure functions, Water Resources Research, 32, 261-270 (1996)

10. O. Karnland, S. Olsson, A. Dueck, M. Birgersso, U. Nilsson, T. Hernan-Hakansson, K. Pedersen, S. Nilsson, T.E. Eriksen, B. Rosborg. Long-term test of buffer material at the Äspö Hard Rock Laboratory, LOT project. Final report on the A2 test parcel. SKB Technical Report TR-09-29 (Stockholm: SKB, 2009)

11. A. Dueck, L.-E. Johannesson, O. Kristensson, S. Olsson S. Report on hydro-mechanical and chemical-mineralogical analyses of the bentonite buffer in Canister Retrieval Test. SKB Technical Report TR-11-07. (Stockholm: SKB, 2011)

12. P. Wersin, L. H. Johnson, I.G. McKinley. Performance of the bentonite barrier at temperatures beyond $100^{\circ} \mathrm{C}$ : A critical review. Phys. and Chem. of the Earth, 32(8-14), 780-788 (2007)

13. A. Gens, J. Vaunat, B. Garitte, Y. Wileveau. In situ behaviour of a stiff layered clay subject to thermal loading: observations and interpretation Geotechnique. 57, 207-228 (2007).

14. M. Mohajerani, P. Delage, J.Sulem, M.Monfared, A.M.Tang, B.Gatmiri. A laboratory investigation of thermally induced porepressures in the CallovoOxfordian claystone. Int. J. Rock Mech. \& Mining Sci. 52, 112-121 (2012)

15. M. Monfared, J. Sulem, P. Delage, M. Mohajerani. A laboratory investigation on thermal properties of the Opalinus claystone. Rock Mech Rock Eng. 44, 735747 (2011)

16. M. Belmokhtar, P. Delage, S. Ghabezloo, N. Conil. Thermal volume changes and creep in the CallovoOxfordian claystone. Rock Mech Rock Eng.v 50, 2297-2309 (2017)

17. I. Gaus, Long Term performance of Engineered Barrier Systems (PEBS). Mont Terri HE-E experiment: detailed design report. Technical Repot NAB 11-001. (Wettingen, Switzerland: NAGRA, 2011)

18. A. Gens. Soil-environment interactions in geotechnical engineering. 47th Rankine Lecture. Géotechnique, 60, 3-74 (2010)

19. S. Olivella, A. Gens, J. Carrera, E.E. Alonso. Numerical formulation for a simulator (CODEBRIGHT) for the coupled analysis of saline media. Engng Comput. 13, 87-112 (1996)

20. A. Gens, R.B. Vasconcelos. HE-E Experiment: Modelling of the HE-E test. Technical Note TN 2019-43 (Mont Terri Project, 2019). 